\title{
SALURAN PEMASARAN BAWANG MERAH PADA KELOMPOK TANI SUKASARI DI DESA BELANDINGAN KECAMATAN, KINTAMANI KABUPATEN BANGLI
}

\author{
Ir. Ni Nengah Yastini, M.P \\ Program Studi Agribisnis, Fakultas Pertanian, Universitas Dwijendra \\ Email : yastini008@gmail.com
}

\begin{abstract}
Abstrak
Di Indonesia, tanaman bawang merah banyak dibudidayakan di daerah dataran rendah yang beriklim kering dengan suhu agak panas dan cuaca cerah. Produksi bawang merah sampai saat ini memang belum optimal dan masih tercermin dalam keragaman cara budidaya tempat bawang merah diusahakan.Bawang merah merupakan salah satu jenis sayuran yang digunakan sebagai bahan/bumbu penyedap makanan sehari-hari dan juga biasa dipakai sebagai obat tradisional atau bahan untuk industri makanan yang saat ini berkembang dengan pesat. Bawang merah menurut sejarah awalnya tanaman ini memiliki hubungan erat dengan bawang bombay, yaitu merupakan salah satu bentuk tanaman hasil seleksi yang terjadi secara alami terhadap varian-varian dalam populasi bawang Bombay. Berdasarkan hal tersebut, diangkat judul penelitian Saluran Pemasaran Bawang merah. Penelitian ini bertujuan: (1) untuk mengetahui saluran pemasaran bawang merah di Kelomok Tani Sukasari di Desa Belandingan, Kecamatan Kintamani, Kabupaten Bangli; (2) untuk mengetahui besarnya marjin pemasaran bawah merah di Kelomok Tani Sukasari di Desa Belandingan, Kecamatan Kintamani, Kabupaten Bangli.Penelitian ini dilakukan di Kelompok Tani Sukasari Di Desa Belandingan, Kecamatan Kintamani, Kabupaten Bangli. Penentuan lokasi penelitian dilakukan dengan metode"purposive sampling"atau dipilih secara sengaja. Jumlah petani sampel yang diambil adalah sebanyak 30 orang petani dari 80 orang petani populasi dengan menggunakan sampel random sampling. Hasil penelitian yang didapat bahwa terdapat dua saluran pemasaran di Desa Blandingan, Kecamatan Kintamani, Kabupaten Bangli yaitu : Saluran I Petani Produsen - Pedagang Kelompok Tani --Super Market - Konsumen Akhir; Saluran II Petani Produsen-Kelompok Tani -Suplayer -Pedagang Pengecer - Konsumen Akhir. Pada saluran I yang paling banyak digunakan oleh petani yaitu sebanyak 24 orang petani(80\%). Sedangkan pada saluran II sebanyak 6 orang petani $(20 \%)$. Hal itu disebabkan karena lebih banyak mendapat keuntungan, dimana biaya pemasaran pada saluran I lebih rendah yaitu Rp525 (1,9\%) dari harga jual per kilogram bawang merah.farmer's share yang didapat oleh petani lebih besar yaitu 92,6\%.. Sedangakan pada saluran II hanya dilalui oleh 6 orang petani(20), karena biaya pemasarannya lebih tinggi yaitu Rp1.300 (5,2,)farmer's share yaitu 88,8\% (lebih rendah dibandingkan dengan saluran I.
\end{abstract}

Kata Kunci: Saluran, Pemasaran, Marjin,Bawang Merah

\begin{abstract}
In Indonesia, the shallot plant is widely cultivated in lowland areas with dry climates with rather hot temperatures and sunny weather. Until now, shallot production has not been optimal and is still reflected in the diversity of cultivation methods where shallots are cultivated. Shallots are a type of vegetable that is used as an ingredient / seasoning for daily food flavoring and is also commonly used as traditional medicine or ingredients for the food industry which is currently growing rapidly. Onion, according to its early history, this plant has a close relationship with onions, which is one of the selected plant forms that occurs naturally against variants in the onion population. Based on this, the research title is the Shallot Marketing Channel. This study aims: (1) to determine the marketing channels of shallots in Kelomok Tani Sukasari in Belaing Village, Kintamani District, Bangli Regency; (2) to find out the amount of red bottom marketing margin at Kelomok Tani Sukasari in the Belaing Village, Kintamani District, Bangli Regency. This research was conducted at the Sukasari Farmers Group in Belaing Village, Kintamani District, Bangli Regency. Determining the location of the study was carried out by means of "purposive sampling" or chosen deliberately. The number of farmers sampled was 30 out of 80 population farmers using random sampling. The results showed that there are two marketing channels in Blandingan Village, Kintamani District, Bangli Regency, namely: Channel I Farmers Producers - Farmer Group Traders Super Market - End Consumers; Channel II Farmers Producers - Farmer Groups - Suplayers - Retailers End Consumers. In channel I, the most widely used by farmers is 24 farmers $(80 \%)$. Meanwhile, in channel II there were 6 farmers (20\%). This is due to more profits, where the marketing costs in channel I are lower, namely Rp525 (1.9\%) of the selling price per kilogram of shallots. Farmer's share obtained by farmers is greater, namely $92.6 \%$. Meanwhile, in channel II only 6 farmers (20) pass through, because the marketing costs are higher, namely IDR $1,300((5,2$,$) the farmer's share is 88,8 \%$ (lower than channel I.
\end{abstract}


Keywords:Channel, Marketing, Margin, Shallot

\section{PENDAHULUAN}

Pembangunan pertanian sebagai bagian dari pembangunan ekonomi nasional dilaksanakan untuk mewujudkan masyarakat Indonesia yang adil dan makmur. Sektor pertanian memegang peranan sangat strategis dalam menjaga stabilitas ekonomi dan politik, mengikuti sektor ini sebagai penghasil bahan pangan seperti beras, jagung, kedele umbi-umbiandan buah-buahan serta sayur-sayuran (Mubyarto,1986; Sedana and Astawa, 2019; Sedana, et al, 2020). Di era globalisasi dan kompotisi yang makin ketat, dan iklim bisnis yang gonjang- ganjing , serta inovasi produk yang dirasa kian penting. Persaingan yang ketat antara perusahaan membuat para pelaku dunia bisnis berani tampil beda dari para pesaingnya. Disamping itu pula,perlu diketahui bahwa kondisi persaingan yang semakin ketat, setiap perusahaan atau produk harus mampu bertahan hidup, bahkan harus dapat terus berkembang. Sektor pertanian merupakan sektor yang paling penting karena menjadi andalan dibidang pangan sehingga sebagian besar kebutuhan manusia dapat dipenuhi. Sektor pertanian perlu ditangani secara sungguh-sungguh agar dapat memberikan manfaat sesuai kebutuhan manusia (Dananjaya dan Pushpha).

Di Indonesia, tanaman bawang merah banyak dibudidayakan di daerah dataran rendah yang beriklim kering dengan suhu agak panas dan cuaca cerah. Produksi bawang merah sampai saat ini memang belum optimal dan masih tercermin dalam keragaman cara budidaya tempat bawang merah diusahakan . Bawang merah merupakan salah satu jenis sayuran yang digunakan sebagai bahan/bumbu penyedap makanan sehari-hari dan juga biasa dipakai sebagai obat tradisional atau bahan untuk industri makanan yang saat ini berkembang dengan pesat. Bawang merah menurut sejarah awalnya tanaman ini memiliki hubungan erat dengan bawang bombay, yaitu merupakan salah satu bentuk tanaman hasil seleksi yang terjadi secara alami terhadap varian-varian dalam populasi bawang Bombay Permadi,1995).

Menurut Darmadi Durianto, (2001) hanya produk yang memiliki persepsi kualitas kuat( perceived quality) yang mampu bersaing merebut dan menguasai pasar. Perceived quality adalah persepsi pelanggan terhadap keseluruhan kualitas atau pelanggan terhadap keseluruhan kualitas atau keunggulan suatu produk atau jasa layanan berkaitan dengan apa yang diharapkan oleh pelanggan. Menjaring pelanggan-pelanggan potensial baru agar pelanggan tidak beralih kepada perusahaan lain memerlukan perceived quality untuk membangun kepercayaan merek. Hal lain yang berperan penting dalam keputusan pembelian lainnya adalah media promosi yaitu periklanan (advertising). Kotler,(2008) salah satu alat utama adalah bauran promosi yaitu iklan (advertising). Periklanan merupakansalah satu alat promosi yang digunakan perusahaan untuk mengarahkan komunikasi persuasif pada konsumen potensial dan masyarakat. Salah satu komoditi pangan di Indonesia adalah bawang merah yang juga merupakan komoditi penting selain beras. Di Indonesia, tanaman bawang merah banyak dibudidayakan di daerah dataran rendah yang beriklim kering dengan suhu agak panas dan cuaca cerah.

Produksi bawang merah sampai saat ini memang belum optimal dan masih tercermin dalam keragaman cara budidaya tempat bawang merah diusahakan.Bawang merah merupakan salah satu jenis sayuran yang digunakan sebagai bahan/bumbu penyedap makanan sehari-hari dan juga biasa dipakai sebagai obat tradisional atau bahan untuk industri makanan yang saat ini berkembang dengan pesat. Bawang merah menurut sejarah awalnya tanaman ini memiliki hubungan erat dengan bawang bombay, 
yaitu merupakan salah satu bentuk tanaman hasil seleksi yang terjadi secara alami terhadap varian-varian dalam populasi bawang Bombay Permadi,1995).

Desa Belandingan Kecamatan Kintamani Kabupaten Bangli merupakan daerah pegunungan beriklim sedang dengan ketinggian $1.050 \mathrm{~m}$ diatas permukaan laut. Mata pencaharian mayoritas penduduk adalah petani. Desa Belandingan merupakan salah satu Desa disebelah timur Kecamatan Kintamani dengan jarak $15 \mathrm{~km}$ dari pusat pemerintahan kecamatan dan $35 \mathrm{~km}$ dari Kabupaten Bangli. Sedangkan jarak dari pusat pemerintahan Provonsi Bali adalah $80 \mathrm{~km}$ dengan luas wilayah 600.100 m2.Salah satu komoditi hasil pertanian di Desa Blandingan Kecamatan KintamaniKabupaten Bangli adalah bawang merah. Desa Belandingan Kecamatan Kintamani Kabupaten Bangli memiliki tingkat kesuburan tanah yang tinggi, sehingga sangat cocok untuk usaha tani bawang merah. Adapun tujuan dari penelitian ini adalah : (1).Untuk mengetahui saluran pemasaran bawang merah di Desa Belandingan Kecamatan Kintamani Kabupaten Bangli. (2). Untuk mengetahui besarnya marjin pemasaran bawang merah di Desa Belandingan Kecamatan Kintamani Kabupaten Bangli.

\section{METODE}

Penelitian dilakukan di Desa Belandingan Kecamatan Kintamani Kabupaten Bangli. Penelitian ini ditentukan secara sengaja (purposive sampling) dengan beberapa pertimbangan sebagai berikut ; (1). Desa Belandingan merupakan salah satu Desa yang terdapat di Kecamatan Kintamani Kabupaten Bangli yang mengusahakan usaha tani bawang merah.(2). Kecamatan Kintamani merupakan salah satu sentral produksi bawang merah di Kabupaten Bangli. Adapun anggota kelompok tani Sukasari Desa Belandingan Kecamatan Kintamani Kabupaten Bangli yang menanam bawang merah sebanyak 80 orang petani. Pada penelitian ini tidak seluruh petani diambil untuk dijadikan obyek penelitian, karena keterbatasan waktu, dana dan tenaga. Oleh karena itu dilakukan teknik sampling yaitu simple random sampling dan jumlah sampel yang diambil sebanyak 30 orang petani. Data yang dikumpulkan pada penelitian ini ada dua jenis data yaitu data primer dan data sekunder. Data primer dikumpulkan dengan cara teknik survai yaitu dengan melakukan wawancara langsung dengan sampel dengan menggunakan daftar pertanyaan atau kuesioner yang telah disiapkan sebelumnya. Sedangkan pengumpulan data sukender diperoleh dari dokumen yang terkait dengan penelitian ini. Data yang terkumpul selanjutnya dianalisis dengan menggunakan rumus :

\section{Persentasemarjin pemasaran}

$$
\mathrm{Mp}=(\mathrm{Pr}-\mathrm{Pf}) / \operatorname{Pr} \times 100 \%
$$

Dimana :

$$
\begin{aligned}
& \text { Mp : Marjin pemasaran } \\
& \operatorname{Pr}: \text { harga bawang merah ditingkat konsumen } \\
& \text { Pf : harga bawang merah ditingkat petani }
\end{aligned}
$$

Keuntungan pemasaran dengan menggunakan rumus :

$$
\text { Kpn }=\text { Psn }- \text { Pbn }- \text { Bpn }
$$

Dimana :

Kpn : Keuntungan lembaga pemasaran ke $-\mathrm{n}$

Psn : Harga jual bawang merah lembaga pemasaran ke-n 
$\mathrm{Pbn}$ : harga beli bawang merah lembaga pemasaran ke-n

Bpn : Biaya pemasaran bawang merah lembaga pemasaran ke-n

Keuntungan adalah penjualan dari keuntungan yang diterima oleh setiap lembaga pemasaran, dapat dirumuskan sebagai berikut :

$\mathrm{Kp}=\mathrm{Kp} 1+\mathrm{Kp} 2+\ldots \mathrm{Kpn}$

Dimana :

Kp : $\quad$ : keuntungan pemasaran bawang merah

$\mathrm{Kp} 1, \mathrm{Kp} 2, \mathrm{Kpn}$ : keuntungan tiap lembaga pemasaran bawang merah

\section{Biaya pemasaran}

Biaya pemasaran dapat dihitung dengan menggunakan rumus :

$\mathrm{Bp}=\mathrm{Bp} 1+\mathrm{Bp} 2+\ldots \mathrm{Bpn}$

Dimana Bp : biaya pemasaran bawang merah

Bp1, Bp2, Bpn : Biaya pemasaran tiap lembaga pemasaran bawang merah.

Suatu saluran pemasaran dianggap efesien secara ekonomi apabila saluran pemasaran tersebut mempunyai nilai persentase marjin pemasaran yang relativ rendah serta bagian yang diterima petani lebih dari $50 \%$.

\section{HASIL DAN PEMBAHASAN}

Saluran pemasaran antara satu dengan saluran bagian lainya merupakan satu kesatuan yang saling bergantung sehingga membentuk sistem saluran pemasaran (marketing channel system). Saluran pemasaran mempunyai andil dalam menyampaikan barang kekonsumen yaitu sebagai agen, bagaimana perantara pemasaran bernegosiasi atas barang milik produsen dengan konsumen. Menurut Kotler, (2006) Saluran pemasaran adalah serangkaian organisasi yang saling tergantung yang terlibat dalam proses untuk menjadikan suatu produk barang atau jasa siap untuk dikonsumsi.

Berdasarakan hasil penelitian yang dilakukan di Kelompok Tani Sukasari yang ada di Desa belandingan Kecamatan Kintamani Kabupaten Bangli terdapat dua saluran pemasaran bawang merah yaitu :

1. Petani produsen- kelompok tani sukasari- super market- konsumen akhir.

saluran pemasaran I ini merupakan saluran yang paling banyak dilalui oleh para petani sampel yaitu mencapai 24 orang (80), karena petani produsen merasa lebih banyak mendapat keuntungan. hal ini disebabkan karena biaya pemasaran pada saluran I lebih rendah dibanding dengan biaya pemasaran pada saluran II.

2. Petani produsen- kelompok tani sukasari- suplayer - pengecer -konsumen akhir.

Saluran pemasaran II ini hanya 6 orang (20\%). Dimana petani responden menjual bawang yang sudah dipanen kepada kelompok tani dan kelompok tani mengelolah lalu kemudian dijual kepada suplayer. Suplayer menjualnya kepada pengecer dan pengecer menjualnyakepada konsumen akhir.

Margin pemasaran dapat didefinisikan sebagai selisih harga antara yang dibayarkan konsumen dengan harga yang diterima produsen. Panjang pendeknya sebuah saluran pemasaran dapat mempengaruhi marginnya. Semakin panjang saluran pemasaran maka semakin besar pula margin pemasarannya, sebab lembaga pemasaran yang terlibat semakin banyak. Besarnya angka marjin 
pemasaran dapat menyebabkan bagian harga yang diterima oleh petani produsen semakin kecil dibandingkan dengan harga yang dibayarkan konsumen langsung ke petani.

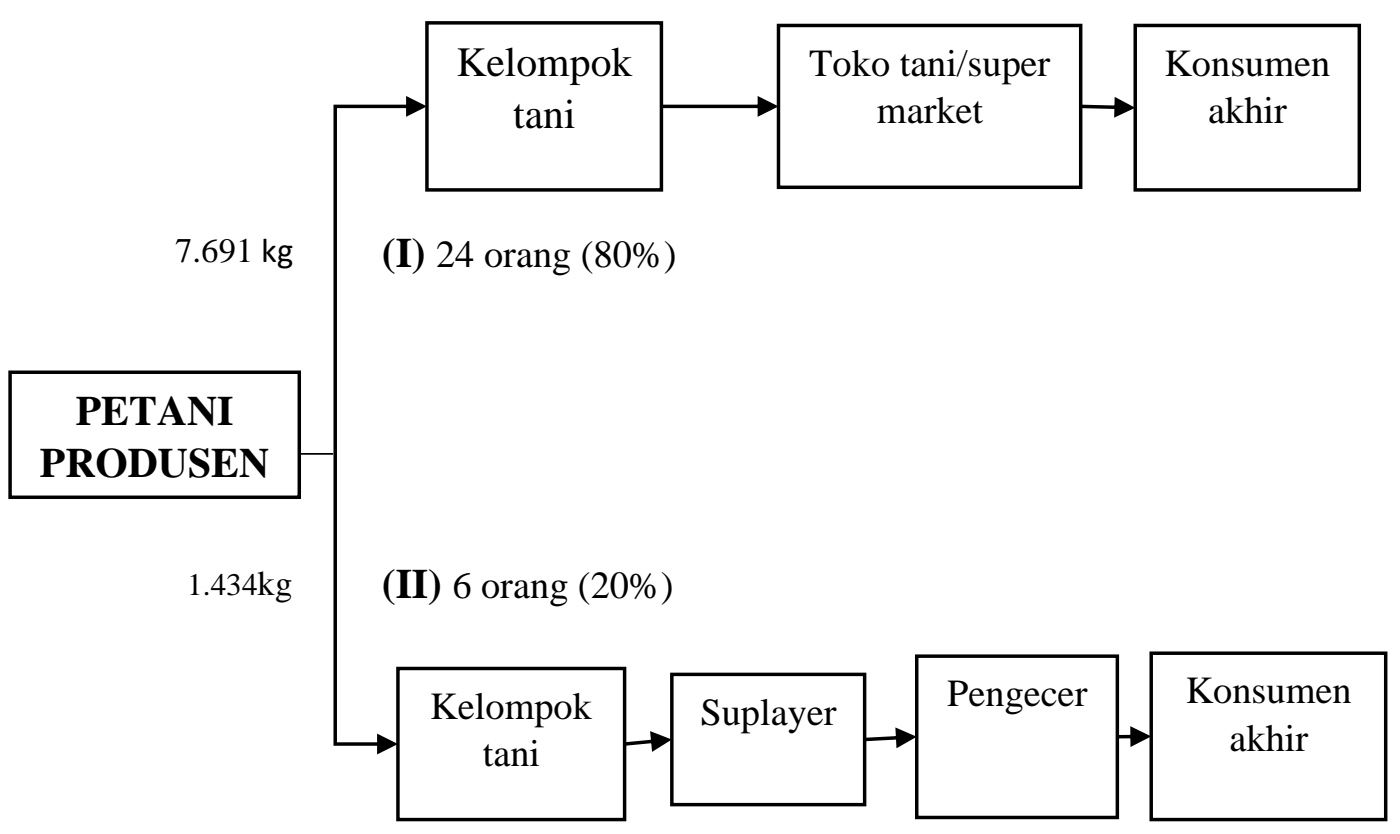

Gambar 1. Skema Saluran Pemasaran Bawang Merah

Tabel 1. Produksi, harga, dan rata-rata pendapatanper petani Bawang Merah Melalui Saluran I dan II

\begin{tabular}{|c|c|c|c|c|}
\hline Saluran & Produksi (kg) & $\begin{array}{c}\text { Harga } \\
(\mathrm{Rp} / \mathrm{kg})\end{array}$ & $\begin{array}{c}\text { Rata-rata pendapatan per } \\
\text { petani (Rp/rata-produksi) }\end{array}$ & Jumlah Petani (orang) \\
\hline I & $7.691(84,28 \%)$ & 25.000 & 8.011 .458 & $24(80 \%)$ \\
\hline II & $1.434(15,72 \%)$ & 22.000 & 5.258 .000 & $6(20 \%)$ \\
\hline Jumlah & $9.125(100 \%)$ & & & $30(100 \%)$ \\
\hline
\end{tabular}

Sumber : Data Primer

Berdasarkan tabel 1, jumlah produksi bawang merah pada saluran I $7.691 \mathrm{~kg}$, dengan harga bawangRp.25.000 per kg,rata-rata pendapatan produksi bawang merah pada saluran I Rp.8.011.458,dengan jumlah petani 24 orang petani. sedangkan pada saluran II jumlah produksi bawang merah 1.434 kg., harga bawang merah Rp.22.000 per kg, rata-rata pendapatan produksi bawang merah Rp 5.258.000,.jumlah petani 6 orang petani. 
Tabel 2. Rata-rata Harga Beli, Harga Jual, Biaya, Keuntungan dan Margin Pemasaran pada Saluran I dan II

\begin{tabular}{|c|c|c|c|c|c|c|c|}
\hline No & $\begin{array}{c}\text { Petani/ } \\
\text { lembaga } \\
\text { pemasran }\end{array}$ & Saluran & $\begin{array}{c}\text { Harga } \\
\text { beli } \\
\text { Rp/kg }\end{array}$ & $\begin{array}{c}\text { Harga } \\
\text { jual } \\
\text { Rp/kg }\end{array}$ & $\begin{array}{c}\text { Biaya } \\
\text { Pemasaran }\end{array}$ & $\begin{array}{c}\text { Keuntungan } \\
(\mathrm{Rp} / \mathrm{kg})\end{array}$ & $\begin{array}{c}\text { Marjin } \\
\text { pemasaran } \\
(\mathbf{R p} / \mathrm{kg})\end{array}$ \\
\hline 1 & $\begin{array}{l}\text { Petani/ } \\
\text { kelompok } \\
\text { tani }\end{array}$ & II & - & $\begin{array}{r}24.475 \\
(92 \%) \\
22.000 \\
(79,85)\end{array}$ & 525 & & \\
\hline 2 & $\begin{array}{l}\text { Toko } \\
\text { tani/suplayer }\end{array}$ & $\begin{array}{l}\text { I } \\
\text { II }\end{array}$ & $\begin{array}{l}25.000 \\
22.000\end{array}$ & $\begin{array}{l}27.000 \\
24.775\end{array}$ & $\begin{array}{l}525 \\
1.300\end{array}$ & $\begin{array}{l}1.475 \\
1.475\end{array}$ & $\begin{array}{l}2.000 \\
2.775\end{array}$ \\
\hline 3 & Pengecer & $\begin{array}{l}\text { I } \\
\text { II }\end{array}$ & $\begin{array}{l}- \\
24.775\end{array}$ & $\begin{array}{l}- \\
27.550\end{array}$ & $\begin{array}{l}- \\
1.300\end{array}$ & $\begin{array}{l}- \\
1.475\end{array}$ & $\begin{array}{l}- \\
2.775\end{array}$ \\
\hline & Jumlah & $\begin{array}{l}\text { I } \\
\text { II }\end{array}$ & & & $\begin{array}{l}1.050 \\
2.600\end{array}$ & $\begin{array}{l}1.475 \\
2.950\end{array}$ & $\begin{array}{l}2.000 \\
5.550\end{array}$ \\
\hline
\end{tabular}

Sumber ; Data Primer

Berdasarkan Tabel 2 bisa dilihat bahwa pada saluran pemasaran I kisaran harga yang diterima petani produsen adalah Rp 24.475/kg. Pada saluran ini petani produsen menjual bawang merah kepada Toko Tani atau Suplayer. Biaya pemasaran dan produksi yang ditetapkan oleh petani produsen atau kelompok tani adalah Rp 525 per kilogram bawang merah, sehingga harga jual kelompok tani pada saluran I adalah Rp 25.000 per kilogram bawang merah. Sedangkan harga beli toko tani atau suplayer mencapai Rp 25.000, dengan biaya transportasi Rp 150, biaya pemasaran Rp 200, dan biaya sewa tempat $R p$ 175. Jadi total biaya pemasaranya adalah 525. Oleh sebab itu harga pokok penjualan pada saluaran I mencapai Rp 25.525. Sedangkan harga yang diterima konsumen akhir adalah Rp 27.000 per kilogram bawang merah. Oleh karenanya keuntungan yang diterima toko tani mencapai Rp 1.475 per kilogram $(5,5 \%)$ dari harga yang dibayar konsumen akhir). Selanjutnya persentase bagian yang diterima oleh petani produsen adalah 92\% dari harga yang dibayar oleh konsumen akhir. Sedangkan marjin pemasaran per kilogram bawang merah adalah Rp 2.000. Data selengkapnya bisa dilihat pada tabel 2 dan tabel 3, dan rincian datanya bisa dilihat pada lampiran I dan II.

Tabel 3. Rata-rata Biaya, Keuntungan, Marjin Pemasaran dan Persentase Bagian yang Diterima Petani Produsen Per Kilogram Bawang Merah pada Masing-masing Saluran Pemasaran.

\begin{tabular}{|c|l|l|l|l|}
\hline $\begin{array}{c}\text { Saluran } \\
\text { pemasaran }\end{array}$ & $\begin{array}{c}\text { Biaya pemasaran } \\
(\mathbf{R p} / \mathbf{k g})\end{array}$ & $\begin{array}{c}\text { Keuntungan } \\
(\mathbf{R p} / \mathbf{k g})\end{array}$ & $\begin{array}{c}\text { Marjin Pemasaran } \\
(\mathbf{R p} / \mathbf{k g})\end{array}$ & $\begin{array}{c}\text { Persentase } \\
\text { bagian yang } \\
\text { diterima } \\
\text { petani }\end{array}$ \\
\hline I & $525(1,9 \%)$ & $1.475(5,5 \%)$ & $2.000(7,41 \%)$ & $92 \%$ \\
\hline II & $1.300(5,2 \%)$ & $1.475(6,0 \%)$ & $2.775(10,07 \%)$ & $79,85 \%$ \\
\hline Jumlah & $1.825(7,2 \%)$ & $2.950(11,5 \%)$ & $4.775(17,48 \%)$ & $171,85 \%$ \\
\hline
\end{tabular}

Sumber : Data Primer 


\section{Analisis Biaya, Keuntungan dan Margin Pemasaran Pada Saluran II}

Saluran pemasaran yang berikut yakni model saluran II Dalam saluran ini, petani menjual bawang merah ke kelompok tani, selanjutnya pedagang kelompok tani menjual kembali ke suplayer, dan suplayer menjualnya kepada pedagang pengecer sebelum akhirnya pedagang pengecer menjual ke konsumen akhir.

Data pada tabel 2 menunjukkan bahwa pada saluran II petani menjual bawang merah ke suplayer dengan harga $\mathrm{Rp} 22.000$,- sedangkan suplayer menjual ke pedagang pengecer dengan harga $\mathrm{Rp}$ 24.775/kg. Kemudian pedagan pengecer menjualnya ke konsumen akhir dengan harga Rp 27.550,- per kg. Keuntungan yang diperoleh suplayer sebesar Rp 1.475,- per kg (6\%), sedangkan biaya pemasaran yang dikeluarkan Rp 1.300,- per kg (5.2 \%) dan margin total sebesar Rp 2.775,- per kg $(11,20 \%)$. Dan keuntungan yang diperoleh pedagang pengecer yaitu sebesar Rp 1.475/kg (6\%), total biaya pemasaran yang dikeluarkan sebesar $\mathrm{Rp} 1.300 / \mathrm{kg}(5,2 \%)$. Total margin pemasaran yang diperoleh pedagang pengecer sebesar $\mathrm{Rp} 2.775 / \mathrm{kg}(10,07 \%)$.

\section{Harga yang diterima petani di tingkat lembaga pemasaran (farmer's share)}

Farmer's share adalah perbandingan bagian yang diterima petani terhadap harga yang dibayar konsumen akhir. Farmer's share berhubungan negatif denganmarjin pemasaran, artinya semakin tinggi marjin pemasaran, maka bagian yang akan diperoleh petani (farmer's share) semakin rendah.

Tabel 4. Bagian harga yang diterima petani di (farmer share) menurut saluran

\begin{tabular}{|l|c|c|}
\hline \multirow{2}{*}{ Saluran pemasaran } & \multicolumn{2}{|c|}{ Farmer's share (100\%) } \\
\cline { 2 - 3 } & Toko Tani/Suplayer & Pedagang Pengecer \\
\cline { 2 - 3 } & $92,6 \%$ & $89,9 \%$ \\
\hline saluran 1 & $88,8 \%$ & \\
\hline
\end{tabular}

Sumber : Data Primer

Berdasarkan tabel 4 di atas dapat dinyatakan bahwa nilai farmer's share merupakan hitungan panjang pendeknya saluran pemasaran. Maka semakin panjang saluran pemasaran maka semakin kecil keuntungan yang dapat diperoleh oleh lembaga pemasaran terakhir. Pada saluran pemasaran I memberikan nilai farmer's share sebesar $92,6 \%$ sedangkan pada saluran pemasaran II memberikan farmer's share sebesar $88,8 \%$. Semakin besar bagian harga yang diterima petani maka saluran pemasaran tersebut sangat efisien. Dengan demikian saluran pemasaran yang paling efisien adalah saluran pemasaran I.

\section{PENUTUP}

\section{Simpulan}

Berdasarkan hasil penelitiandan analisisyang telah dilakukan di Desa Belandingan, Kecamatan Kintamani Kabupaten Bangli, dapat ditarik disimpulkan yaitu :

1. Saluran pemasaran bawang merah yang terjadi di Desa Belandinga dikelompok tani Sukasari terdapat dua tipe saluran pemasaran. Saluran pemasaran I adalah : Petani produsen - kelompok tani Sukasari - super market- konsumen akhir sebanyak 24 orang (80\% Dalam saluran II adalah : Petani produsenkelompok tani Sukasari- suplayer- pedagang pengecer -konsumen akhir sebanyak 6 orang (20\%). 
2. Marjin pemasaran pada saluran pemasaran I sebesar Rp. 2.000 per kg dengan biaya pemasaran $\mathrm{Rp} 525$ per kg sedangkan marjin pemasaran pada saluran II adalah Rp2.775 per kg dengan biaya pemasaran Rp1.300 per kg

\section{Saran}

Berdasarkan kesimpulan diatas dapat disarankan beberapa hal yaitu : (1).Untuk memperoleh keuntungan yang maksimal maka petani bawang merah kelompok tani Sukasari sebaiknya menjual hasil produksinyamelalui saluran I, karena hasil menunjukan bahwa saluran I merupakan saluran yang paling efisien. (2). Bagi para pedagang perantara disarankan agar saling mengadakan interaksi terutama dalam hal menentukan keseragaman harga, baik harga pembelian maupun harga penjualan.

\section{DAFTAR PUSTAKA}

Anonim. 2005. Bawang merah. diakses dari http://id.wikipedia.org/wiki/Bawang merah

Antara. 2006. Prinsip Pemasaran . Jakarta .Erlangga

Buldani. 2011. Manajemen Pemasaran. Jakarta.: Erlangga

Dananjaya, I.G.A.N. dan A.A.G. Pushpha.2019. Bauran Pemasaran Asparagus (Asparagus oficinialis L) pada Koperasi Tani Mertanadi di Desa Pelaga, Kecamatan Petang Kabupaten Badung. Jurnal dwijenAGRO, Vol. 9 No. 1.

Dinas Pertanian, Perkebunan, dan Kehutanan Kabupaten Bangli. 2012. Dinas Pertanian, Perkebunan dan Kehutanan. Bangli.

Durianto Darmadi, 2001. Strategi Menaklukan Pasar Melalui Riset Kualitas dan Prilaku Merek.,PT. Gramedia Pustaka Utama, Jakarta 2

Hamid. 1972. Tataniaga Pemasaran. Institute Pertanian Bogor : Bogor.

Kotler, P. 2006. Prinsip-prinsip Pemasaran. Jakarta : Erlangga.

Kloter, P. (1997). Manajemen Pemasaran. Erlangga : Jakarta

Mubyarto. (1986). Pengantar Ekonomi Pertanian. LP3ES, Jakarta.

G Sedana, I N.D Astawa. 2019. Establishment of Inclusive Business on Coffee Production in Bali province: Lesson from the Coffee Development Project in Nusa Tenggara Timur Province, Indonesia. Asian Journal of Agriculture and rural Development Vol. 9, Issue 1:111-122.

Sedana, G. and A. Rahmat. (2020). Alternative Policies to Strengthen the Traditional Irrigation System for Supporting the Food Security Program: Case of The Subaks' System in Bali, Indonesia. International Jour nal of Advanced Science And Technology, Vol. 29, No. 7s: 973-984

Sedana, G., A. Rahmat, and K. Wirawan. 2020. Development Strategies to Manage Village Forest In Bali. Journal of Advance Research in Dynamical and Control System, Vol. 12, Issue 6: 2065-2075. 